\title{
Load planning processes to enhance cargo compartment utilization
}

Department of Operational Sciences, Air Force Institute of Technology, Wright-Patterson AFB, Ohio, USA

Robert E. Overstreet

Department of Supply Chain and Information Systems, Iowa State University, Ames, Iowa, USA, and

Matthew A. Douglas

Department of Operational Sciences, Air Force Institute of Technology, Wright-Patterson AFB, Ohio, USA

\begin{abstract}
Purpose - The United States Air Force often provides effective airlift for cargo distribution, but is at times inefficient. This paper aims to address the under-utilization of military airlift cargo compartments that plagues the airlift system.

Design/methodology/approach - The authors examine seven techniques designed to increase cargo compartment utilization and increase airlift utilization rates. The techniques were applied through load planning software to 30 real-world movements consisting of 159 sorties. They then ran each post-technique movement through a modeled flight environment to obtain cycle movement data. The metrics gained from both the load planning software and the modeled environment were regressed to provide statistical understanding regarding how well each technique influenced cost savings.

Findings - The results showed a 24 per cent elimination of aircraft required and a savings of $\$ 14.5 \mathrm{~m}$. Extrapolation of the authors' findings to four years of airlift mission data revealed an estimated annual savings of $\$ 1.6 \mathrm{bn}$.

Originality/value - This research effort provides multiple options to improve the efficiency and effectiveness of military airlift.
\end{abstract}

Keywords Aircraft loading, Aircraft optimization, Airlift utilization, Compartment packing, Load planning

Paper type Research paper

\section{Introduction}

The US national defense policy relies heavily on rapid global mobility to project forces around the globe at a moment's notice, which serves to deter enemies from carrying out their malicious plans against America and its allies. Senior leaders at all levels are concerned about how to maintain this security posture while coping with a 13.7 per cent decline in

(C) In accordance with section 105 of the US Copyright Act, this work has been produced by a US government employee and shall be considered a public domain work, as copyright protection is not available. Published in Journal of Defense Analytics and Logistics. Published by Emerald Publishing Limited.

Received 14 July 2017 Revised 26 September 2017 6 November 2017 Accepted 6 November 2017 
JDAL 1,2

138

military spending since 2010 (Harrison, 2014). This research examines techniques to enhance cargo capability of US military airlift aircraft while simultaneously realizing significant cost savings.

The responsibility of aircraft utilization falls on the shoulders of loadmasters for commercial aircraft and military/air transportation load planners for military aircraft (Ng, 1992; Limbourg et al., 2012). For the most part, air transportation load planners are constrained by the current 463L pallet rail system. This system was designed in the 1950s to expedite the time required for on-load and off-load during cargo operations. The 463L system ensures that aircraft floor space is used to maximum efficiency by dividing the horizontal space into equivalent pallet positions (PP), but falls short in efficiently using most of an aircraft's available vertical capacity as shown in Plate 1. We propose that providing air transportation load planners and cargo build up personnel with a set of techniques designed to ensure they can load fewer but heavier cargo aircraft will achieve significant cost savings. Not for the purpose of increasing profits as studied by Lau et al. (2009), but rather to ensure capability with a reduced budget. Other benefits may include reduced operations tempo for aircrews, less wear and tear on the military's aging aircraft fleet, and decreased environmental effects of fuel consumption.

Thus, the purpose of this study is to examine multiple aircraft load planning techniques to determine which, if any, may offer significant opportunities for load planners to maximize the use of aircraft cargo space and ultimately save taxpayer money. The remainder of this article is structured as follows. In the next section, we identify and describe eight aircraft load planning techniques that we evaluate. We then provide a review of the methodology to include our assumptions and limitations. We present the results for each of the aircraft load planning techniques and conclude with a discussion of the implications of the total savings that could be achieved using these techniques.

Plate 1.

Wasted vertical space example

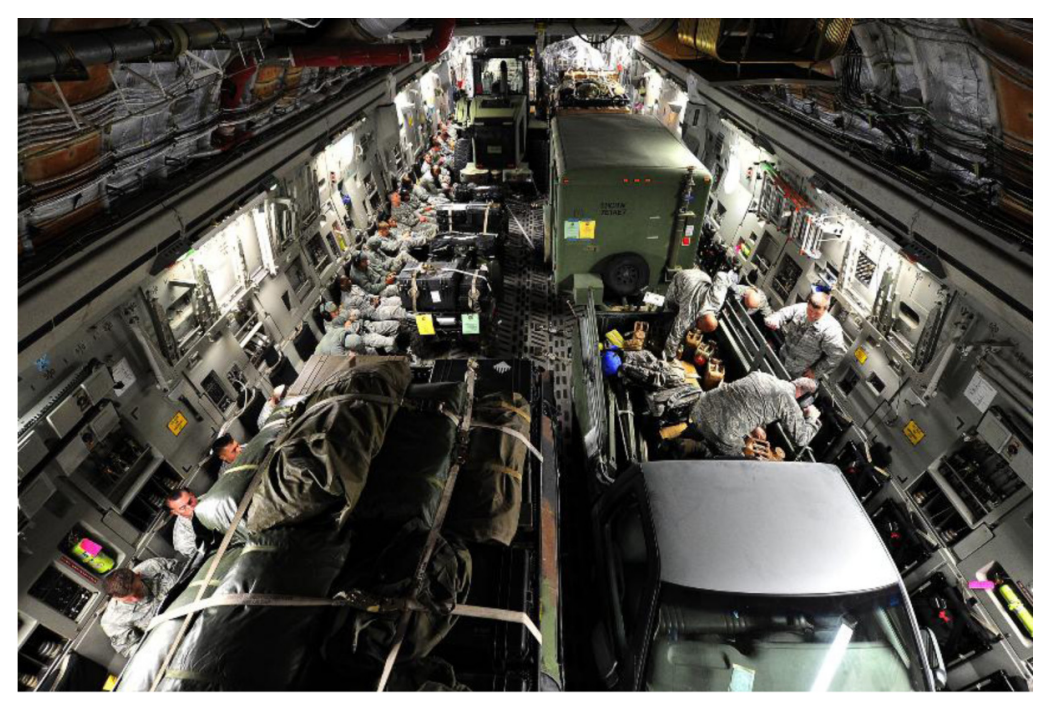

Source: Gyokeres (2012) 


\section{Load planning}

Past literature has made important contributions to our understanding of cargo load planning and the optimization of commercial aircraft capability. Research by Lau et al. (2009) focused on profit versus space utilization. Their simulations showed that heuristics and genetic algorithms outperformed simulated annealing, Tabu search and branch-and-bound methods when considering multi-pallet loads for commercial cargo aircraft. Limbourg et al. (2012) developed a mathematical model and tested it on real world cargo data collected from a commercial industry partner. Their mixed integer processes linear program provides an optimal solution that efficiently calculates the center of gravity precisely, which reduces stress on the aircraft and improves maneuverability. Other studies that attempt to optimize individual aircraft loads have also examined improving fuel consumption (Mongeau and Bes, 2003), reducing the total number of plane loads ( $\mathrm{Ng}, 1992)$, and reducing the time required to produce an acceptable load plan (Fok and Chun, 2004).

Despite advances in commercial cargo loading and decades of internal research on increased utilization of military cargo aircraft (Cochard and Yost, 1985; Abalateo and Lee, 1993; Chocolaad, 1998; Wilson, 2011; Reiman et al., 2015), the US Air Force is not using its cargo aircraft efficiently. The following paragraphs describe various available techniques to increase the use of US Air Force aircraft cargo capacity. The first three techniques are intended to better utilize the vertical space for each PP. The other techniques seek to better select, load plan, and route cargo aircraft.

\section{Bi-level airlift loading system}

This technique allows for two 463L pallets to share the same PP by stacking one pallet on top of another pallet as shown in Plate 2. Developed by US Air Force engineers, the system was specifically designed to increase fleet fuel efficiency by increasing vertical utilization within cargo aircraft (Reiman et al., 2015). The bi-level airlift loading system (BALS) system adds approximately 850 pounds to the weight of the 463L pallet. It can support up to 6,000 pounds on the bottom pallet and another 3,000 pounds on top pallet. The BALS system has been tested and approved for use in US aircraft (Vatcher and Maynard, 2004).

\section{Tonneau covers}

Similar to BALS, Tonneau covers represent another stackable technique for small rolling stock. The cover is installed over a truck bed and can accommodate another small piece of rolling stock such as an all-terrain vehicle, light cart or generator. The system can also be used as a storage option for loose pieces of cargo and has the ability to free up pallet positions that have extremely low vertical utilization rates (Wilson, 2016).

\section{Aggregation}

Aggregation is the simple technique of breaking down small pallets and redistributing the cargo to other pallet positions (e.g. baggage pallets, food pallets and water pallets). The aggregation of the smaller cargo into empty trailers, internal slingable container units (ISUs), on top of other 463L pallets, or in available vehicle bays as shown in Plate 3 on the same mission would eliminate these pallet positions with low vertical utilization rates (Wilson, 2016). The aggregation technique relies heavily on the amount of data the original load planner incorporated into the load plan. If a cargo description was not loaded into a 


\section{JDAL \\ 1,2}

Plate 2.

4 PPs consolidated to 2 PPs using BALS

\section{Plate 3.}

Empty vehicle bay with adjustable netting

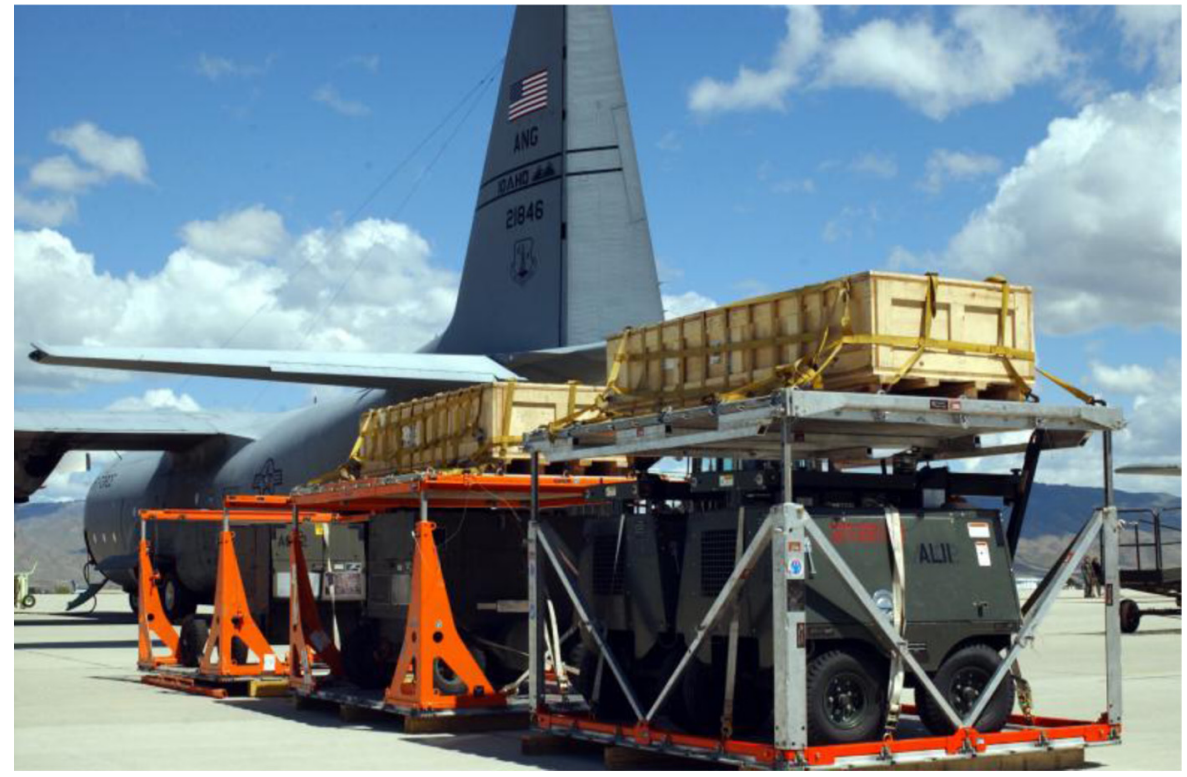

Source: Vincelli (2004)

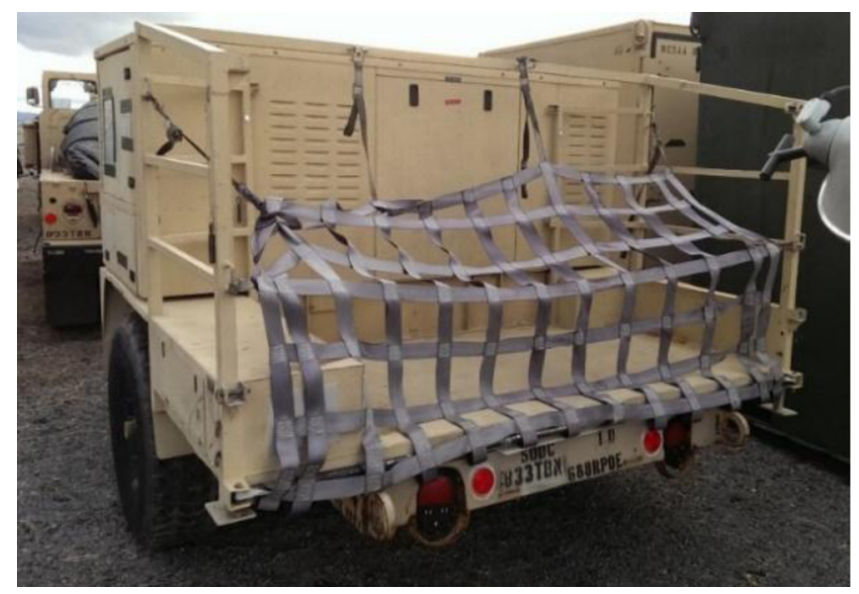

pallet's content listing, then it would be difficult to determine if the pallet can be broken down or if it must remain intact as one solid piece of cargo.

\section{Dual rail swap}

The C-17A's and the C-5B/M's cargo compartments are wide enough to support dual rail loading. Cargo can be loaded side by side on both the right and the left side of the aircraft. 
When rolling stock is centerline loaded into an aircraft's cargo compartment, the functionality of the dual rail system is lost for the PP holding the rolling stock. This loading technique reassigns all centerline loaded rolling stock to a more efficient dual rail position if the rolling stock's weight and dimensions meet the requirements for dual rail loading. Outsized rolling stock remain centerline loaded if the weight, width, or height exceed the limits of the dual rail positions available.

\section{C-17A cargo compartment configuration}

As depicted in Figures 1 and 2, the C-17A has the unique ability to carry 463L pallets in the aerial delivery system (ADS) configuration, which accommodates a single row of 11 pallets, or the logistic delivery system (LGS), which accommodates two rows of 9 pallets each (18 total). The constraint of the ADS system is that all 463L pallet trains have to be centerline loaded and denies access to the dual rail LGS system that uses the space of the aircraft floor more efficiently. For the purpose of this research, all trains located on C-17A aircraft in the ADS configuration were rebuilt into the LGS configuration to use PPs on both sides of the aircraft.

\section{Passenger re-placement}

Many movements analyzed in this research involve a mix of passengers and cargo. Passengers on cargo aircraft must be seated in front of palletized netted cargo by at least 30 inches (Air Mobility Command, 2014). The way in which passengers are positioned can affect the usable cargo loading area of C-17A and C-130J aircraft. Passenger positions do not affect the $\mathrm{C}-5 \mathrm{~B} / \mathrm{M}$ cargo loading area because passengers and cargo are separated into different levels of the aircraft. Rolling stock and loose cargo are not restricted by the segregation requirements of netted palletized cargo. Passengers can be loaded directly across, in front of, or behind rolling stock and loose loaded cargo.

Additional space for cargo placement would become available if passengers were placed strategically to meet airlift requirements. The C-17A is equipped with 53 total sidewall seats that are divided up along each side of the aircraft's fuselage (Department of the Air Force, 2010). If both sides are seated with passengers, then netted palletized cargo can only be loaded in the less efficient ADS configuration. However, if passengers are moved to only one side of the aircraft, then netted palletized cargo can be loaded on the adjacent side in the LGS
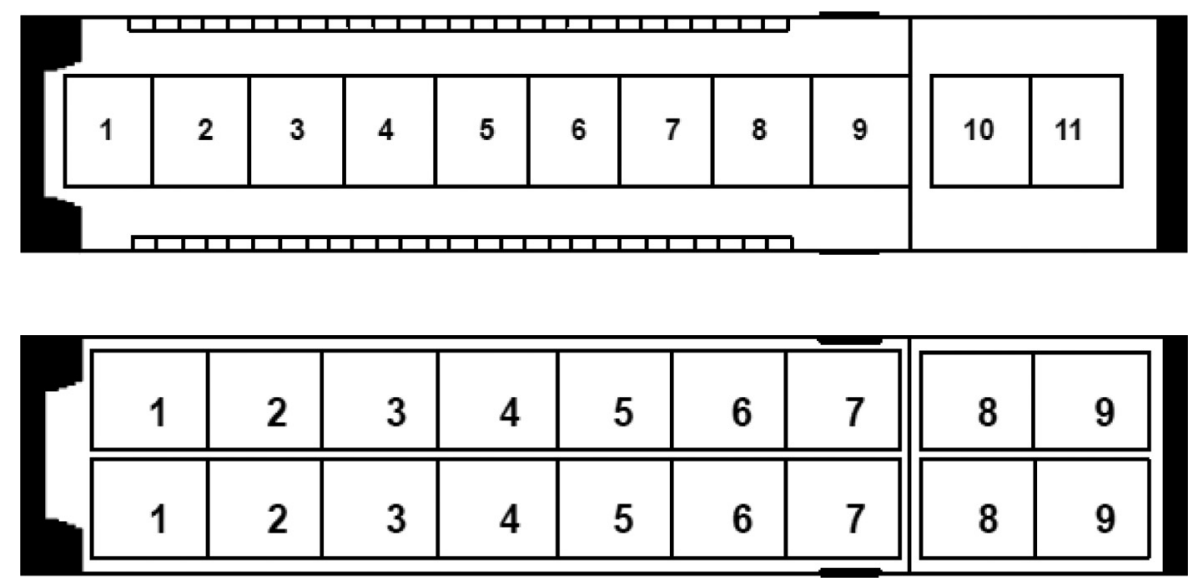

Load planning processes 
JDAL 1,2

configurations. This technique allows rolling stock to be loaded in the remaining space between the passengers and palletized cargo.

The C-130J has optional side line and center line seats that come in a web bench style arrangement. This means that if one passenger is seated, then seating for up to eight must be pulled down and installed onto the cargo floor. It is an all-or-none type system and poor placement of passengers can result in losing an entire PP, which represents up to 12.5 per cent of a C-130J's total cargo loading area.

\section{Use of cargo throughput optimized routing}

Load planners generally use standard aircraft available cabin loads (ACLs) for cargo aircraft movements. However, a trade off exists between the cargo payload and how far an aircraft is capable of flying. As reported by the USAF Scientific Advisory Board (1997), the chart in Figure 3 shows how much weight a cargo aircraft can carry based on the range it must travel. However, load planners are directed to use standard planning ACLs regardless of aircraft flight distance and number of refueling stops. For example, adding a single refueling stop in the middle of 4,000 nautical mile sortie would more than double the ACL for both the C-17A and the C-130J and would nearly double the ACL for the C-5B/M. Using the movement's Cargo Throughput Optimized Routing ACL in this research compared to the planning ACL substantially increased payload capacity enhancing the ability to use the other cargo aggregation techniques.

\section{Aircraft selection}

Maywald (2016) used heuristics in his research to show how the airlift community can realize cost savings by increasing the aircraft diversity used in moving cargo. Many of the load plans analyzed in this research use the same airframe for every chalk in the movement

Figure 3. Payload to range trade ratio

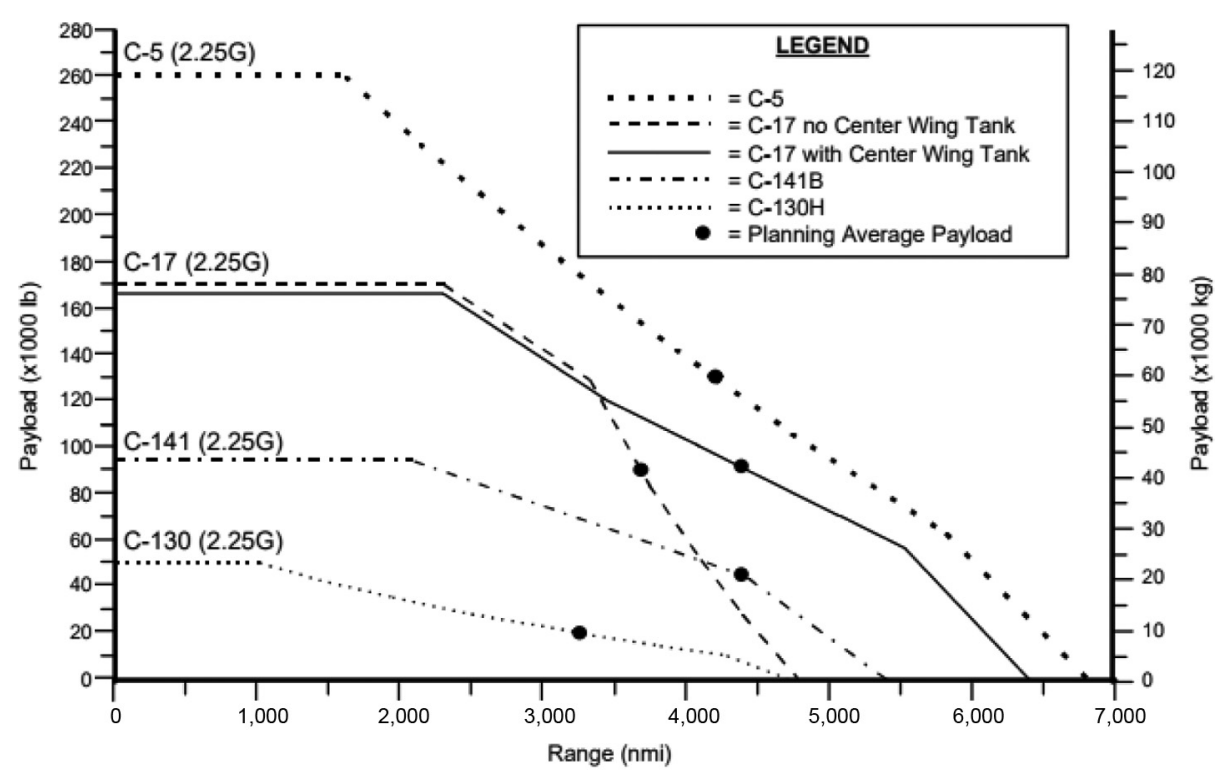

Source: USAF Scientific Advisory Board (1997) 
plan. If an aircraft cannot be eliminated from a movement plan using the other techniques and the cargo can fit on a smaller aircraft, then a smaller aircraft was used. C-5B/M aircraft were downgraded to a C-17A aircraft and C-17A aircraft were downgraded to a C-130J processes aircraft if at all possible.

\section{Methodology}

\section{Data collection}

Data collected for this research came from three individual liaisons from air cargo terminals located in Washington, NJ, and South Carolina. The Integrated Computerized Deployment Execution System (ICODES) Information Resource (IR) database was searched for movements that took place April through October 2016 using a sub-conveyance search filter. A total of 30 movements were collected representing 159 individual aircraft sorties. The original movements were represented in the standard .GLP file formatted for the web based ICODES load planning application.

All data samples collected met three specific criteria: movements contained only military airlift (C-130J, C-17A or C-5B/M), movements had at least two aircraft loads planned to move, and all the cargo associated with the movement terminated at the same Aerial Port of Debarkation (APOD). We deemed any sample that failed to meet those requirements outside the scope of this study.

\section{ICODES}

Once we obtained a data sample, evaluated that sample for all three requirements, and presented that sample in a .GLP ICODES format, we rearranged the cargo using the following load planning utilization process:

- Identify and record the location of every empty PP located in the movement.

- Identify and record the location of every piece of centerline rolling stock that could be moved to one side of a dual rail aircraft (i.e. C-5B/M and C-17A).

- Identify and record which rolling stock contained large storage areas (truck beds, trailers, etc.) for the potential use of Tonneau covers. This technique used ICODES's Mobile Land function. The Mobile Land function requires the truck bed or trailer height to be listed within the cargo's sub-data set.

- Identify low profile pallets with the same type of cargo (e.g. baggage, food, water, or hazmat) for aggregation into storage compartments, vehicle cabins or loose loaded onto other 463L pallets. This technique used ICODES Put Cargo Into function for placement inside of objects and used the ICODES Load Cargo Onto function for restraining cargo down on top of other 463L pallets.

- Identify and record the location of all ADS trains found on C-17A aircraft for LGS reconfiguration consideration.

- Identify and record all cargo (463L pallets, outsized loose cargo and rolling stock) that weighed 6,000 pounds or less and had a height of 64 inches or less for possible BALS combinations. This technique used ICODES's Stack Cargo function. We added 850 pounds to the gross weight of combined pallets to compensate for the weight of the BALS.

Once we completed all of the steps above, we totaled the number of PPs and eliminated the first aircraft that became empty. If we could not eliminate an aircraft from the movement, then we attempted to scale the aircraft down to a smaller 
JDAL 1,2

airframe (e.g. C-17A to C-130J). Once a PP was freed using one or more of our load planning techniques, we brought forward cargo from the remaining aircraft. This pattern continued until the last aircraft was eliminated from the movement or scaled down to a smaller airframe.

\section{Route analyzer}

The second phase of the methodology included running both the original movement and the post process movement through the Route Analyzer (Reiman, 2014). The application determines the optimal routing for the movement based on maximum cargo throughput and reports how much fuel was used, cycle time needed, and cost of movement based on the weight of the cargo in each aircraft. The application's output provided two key metrics (cycle fuel and cycle cost) to compare and contrast the original movement against the post process movement.

We evaluated each aircraft sortie once for the original payload and a second time using the post process payload from the ICODES's .GLP load plan file. The results were saved on each individual aircraft to the same spreadsheet until the entire movement was completed. Data from the original movement were recorded under the heading "Original Movement" and data from the post process movement was recorded under the heading "New Movement". The data recorded under each section include the number of aircraft needed, aircraft type, weight of cargo, routing, maximum ACL for route, utilization rate, cycle fuel, and cycle cost. An example of one small movement's results is listed in Table I.

\section{Assumptions and limitations}

Typically, an exemption to relax hazardous cargo air movement requirements by allowing load planners to place incompatible hazardous items closer together is requested from higher headquarters as part of the airlift mission execution documentation. We assumed that all missions were approved for deployment under the relaxed requirements

\begin{tabular}{|c|c|c|c|c|c|c|c|}
\hline \multirow[b]{2}{*}{$\#$ of $\mathrm{A} / \mathrm{C}$} & \multirow[b]{2}{*}{$\mathrm{A} / \mathrm{C}$ type } & \multicolumn{4}{|c|}{ Original movement } & \multirow{2}{*}{$\begin{array}{l}\text { Cycle fuel } \\
\text { (Klbs) }\end{array}$} & \multirow[b]{2}{*}{ Cycle cost } \\
\hline & & Cargo (lbs) & \multicolumn{2}{|c|}{ Route max ACL (lbs) } & Utilization rate & & \\
\hline Chalk1 & C-17A & 16436 & \multicolumn{2}{|c|}{163,880} & $10.03 \%$ & 402.98 & $\$ 402,316.83$ \\
\hline Chalk2 & C-17A & 33300 & \multirow{2}{*}{\multicolumn{2}{|c|}{163,880}} & $20.32 \%$ & 418.84 & $\$ 409,814.40$ \\
\hline Chalk 3 & $\mathrm{C}-5 \mathrm{M}$ & 49736 & & & $21.58 \%$ & 472.56 & $\$ 452,129.31$ \\
\hline Totals & & 99472 & \multicolumn{2}{|c|}{230,490} & $\mu 17.31 \%$ & 1294.38 & $\$ 1,264,260.54$ \\
\hline \multicolumn{8}{|c|}{ Post technique movement } \\
\hline Chalk1 & C-17A & 41566 & \multicolumn{2}{|c|}{163,880} & $25.36 \%$ & 425.22 & $\$ 408,240.12$ \\
\hline Eliminated & C-17A & Eliminated & \multirow{2}{*}{\multicolumn{2}{|c|}{$\begin{array}{c}\text { Eliminated } \\
230,490\end{array}$}} & Eliminated & Eliminated & Eliminated \\
\hline Chalk 2 & C-5M & 57906 & & & $25.12 \%$ & 477.96 & $\$ 418,285.69$ \\
\hline Totals & & 99472 & & & $\mu 25.24 \%$ & 903.18 & $\$ 826,525.81$ \\
\hline \multicolumn{3}{|c|}{ Distance (NM) } & \multicolumn{2}{|c|}{ RESULTS } & \multicolumn{3}{|c|}{ Techniques used } \\
\hline & \multirow{2}{*}{\multicolumn{2}{|c|}{$\begin{array}{l}4988.29 \\
4909.31\end{array}$}} & Savings: & $\$ 437,734.73$ & \multirow{3}{*}{\multicolumn{3}{|c|}{$\begin{array}{l}\text { Dual Rail Switch: x6 } \\
\text { Pax Re-Placement: x1 }\end{array}$}} \\
\hline C-17: & & & Fuel Saved(Klbs) & 391.2 & & & \\
\hline C-130J: & N/A & & A/C Eliminated: & $1 \times \mathrm{C}-17 \mathrm{~A}$ & & & \\
\hline \multirow[t]{3}{*}{ Average: } & \multirow[t]{3}{*}{4948.8} & & C-17 UTE & $10.19 \%$ & & & \\
\hline & & & $\begin{array}{l}\text { Increase: } \\
\text { C-5 UTE }\end{array}$ & $3.54 \%$ & & & \\
\hline & & & Increase: & & & & \\
\hline
\end{tabular}

Table I.

Movement comparison example
C-5 UTE
Increase: 
(Department of the Air Force, 2012). We also assumed that all aircraft follow a cycle routing (i.e. once the aircraft reached the intended destination, it would eventually return to the point of origin).

This research used maximum aircraft ACLs defined by how much weight an aircraft could carry based on the longest distance sortie of its route to the final destination. To put this in perspective, the normal planning ACL for a C-130J is limited to 40,000 pounds (Air Mobility Command, 2014). However, the optimal routing of the aircraft may increase the C130J ACL to 50,000 pounds in some unique circumstances. It is extremely difficult to meet the maximum ACL of C-17A and C-130J-30. These aircraft normally reach their volume limit before reaching their maximum ACL (Nance, 2009; Gray, 2010). The load plans collected for this research were created using generic planning ACL as the aircraft's limiting weight factor. The load plans developed with the efficiency enhancing techniques used the maximum ACL allowable for maximum cargo throughput routing for a given Origin to Destination (OD) pair.

\section{Analysis}

Before discussing the analysis of the individual techniques, it is important to note the relationship between distance and movement size. Some analysis of the techniques below show a negative trend line where using more of a specific technique resulted in less savings. This is likely a result of those specific techniques being used more on movements that had shorter distances, smaller movement size or both. In the paragraphs that follow, we address each of the proposed techniques.

\section{Bi-level airlift loading system}

The BALS technique was used 129 times on 22 of the 30 movements analyzed and represented a 1 for 1 ratio of PPs saved. The 129 PPs saved can account for the elimination of 7 fully loaded C-17As. The BALS system was highly versatile across all platforms, but benefited the most from the C-17A's vertical capacity.

\section{Tonneau covers}

The Tonneau cover technique was used a total of 13 times on 7 of the 30 movements analyzed and represented a 1 for 1 PP savings. The elimination of 13 PPs is equivalent to approximately 1.5 fully loaded C-130J-30 aircraft. This technique was not frequently used. The problem was that a movement had to contain both a compatible piece of rolling stock with a flat bed and rolling stock small enough to fit on the bed. Tonneau covers also had to compete directly with the more versatile BALS technique and was used when a matching BALS combination could not be found. The Tonneau covers will most likely benefit units that deploy often with multiple trucks and smaller rolling stock. This technique was not as influential on cost savings as the others, but was still effective. When Tonneau covers were used, we observed a significant increase in vertical utilization from that movement.

\section{Aggregation}

Aggregation had a significant influence on cost savings even though the use of the technique was quite limited by how much detail of a pallet's contents was input into ICODES by the original load planner. This technique was used a total of 37 times on 12 of the 30 movements analyzed. The 37 PPs saved by using this technique eliminated 2 fully loaded C-17A aircraft. Some increase in vertical utilization was observed; however, a couple 
JDAL 1,2

of aggregated items were placed inside of rolling stock and did not exceed the height of the parent vehicle.

\section{Dual rail swap}

The dual rail swap technique was used a total of 100 times on 15 of the 30 movements analyzed. The technique reduced the number of PPs needed by 158, the equivalent of approximately 8.5 fully loaded C-17A aircraft. The dual rail swap technique did not directly translate into an increase in vertical utilization, but it did open up a significant number of PPs that would not have otherwise been used.

\section{C-17A cargo compartment configuration}

Switching C-17A center loaded ADS trains into the more efficient side by side LGS train configuration increased utilization. This technique freed up a total of 46 PPs that were either eliminated from the movement or provided an opportunity to accept more cargo that would use additional vertical capacity. We used this technique on 5 of the 30 movements analyzed and the 46 PPs freed up eliminated the need for approximately 2.5 fully loaded C-17As.

\section{Passenger re-placement}

Passenger re-placement could not be evaluated against the other techniques as their results varied too much to translate into PPs saved. In some movements, moving one passenger created more available space and in other movements several passengers had to be moved to create the same space. In some rare cases, passengers had to be moved to accommodate other techniques such as the ADS/LGS train switch and the dual rail switch techniques. Another problem was that the other techniques had the opportunity to be used across all 30 cargo movements, whereas the passenger re-placement technique was at a disadvantage, as it could only be used with movements where passengers were present.

Mostly, the passenger re-placement technique was simply a way to move passengers from an eliminated aircraft to an aircraft that was still included in the movement from posttechnique results. If these passengers were moved from a C-130-J-30 or a C-17A to a C-5B/M, then the results were even harder to track because the $\mathrm{C}-5 \mathrm{~B} / \mathrm{M}$ does not share its passenger compartment with its cargo floor as do the other two aircraft. The passenger re-placement technique was used on 19 of the 30 movements analyzed.

\section{Cargo throughput optimized route available cabin loads}

Using cargo throughput optimized route ACL as the limiting weight factor over planning ACL increased the capacity of nearly every single sortie found in this movement. However, the post technique movements only needed to expand past their original planning ACL a total of 14 of the 159 sorties. In this research, 145 aircraft (91.2 per cent of original) ran out of available floor space before reaching the maximum routing ACL limits (Chao and Li, 2015). This further supports the need for techniques that increase vertical utilization. However, the additional weight needed through cargo throughput optimized routing ACL varied greatly between the 13 aircraft that did benefit from the technique.

\section{Results}

We analyzed 30 movements that included 159 sorties. Using all of our techniques, we eliminated 34 out of 137 (25.5 per cent) of the C-17A aircraft, 2 out of 14 (14.3 per cent) of the 
C-5B/M aircraft and 2 out of 8 (25 per cent) of the C-130J-30 aircraft. Additionally, 26 aircraft (16.4 per cent of original sorties) were scaled down to a smaller aircraft.

The utilization increase found from an individual movement was calculated by the following equation:

$$
\frac{\sum_{i=1}^{n} \gamma_{i}}{n \beta}-\frac{\sum_{i=1}^{n} \propto_{i}}{n \beta}
$$

Load planning processes

where:

$\alpha=$ Original sortie cargo weight;

$\gamma=$ Post technique sortie cargo weight;

$n=$ amount of sorties by mission design series from a single movement; and

$\beta=$ Cargo throughput optimized route ACL.

The average utilization increase, as measured by sortie cargo weight, recorded across all 30 movements was 18.47 per cent. The average increase in C-17A utilization rates was 20.69 per cent, and the average increase in $\mathrm{C}-5 \mathrm{~B} / \mathrm{M}$ utilization rates was 11.97 per cent. An increase in C-130J utilization rates was observed as well, but was mostly due to the underutilization of the airframe in the original movements where only one or two PPs were used.

The total savings for all movements analyzed was $\$ 14,508,979$ with an average savings of $\$ 483,633$ per movement ( $\$ 91,251$ per sortie). These cost savings were regressed over five of the techniques (Table II). The range spanned from the smallest savings of $\$ 101,855$ to the largest of $\$ 1,647,695$. The average cost savings for a 1 per cent utilization increase amounted to $\$ 26,185$. A total of $14,579,490$ pounds of fuel was saved through aircraft elimination and aircraft selection as a direct result of the techniques used. The average fuel savings observed over the 30 movements amounted to 485,980 pounds per movement or 91,695 pounds per sortie.

These savings relied heavily on the distance between the movement's APOE and APOD. In one movement, for example, three C-17As were eliminated and another two C$17 \mathrm{As}$ were scaled down to two C-130Js, which resulted in a savings of $\$ 464,640$. However, as the sorties only flew approximately 1,400 miles, the same savings were achieved from a movement where only one C-17A was eliminated, but moved over 5,000 miles.

The second biggest factor on cost savings was the number of aircraft, represented by total PPs involved in a movement. Larger movements saw greater cost savings over smaller movements that shared a similar APOE and APOD distance set. This was as expected, due to a larger set of aircraft available from which to eliminate or scale down. As this research covered three different sized aircraft, PPs were used as the standardized metric for original

\begin{tabular}{lrrrrr}
\hline Technique & \multicolumn{1}{c}{$\boldsymbol{c}$} & Standard error & Test statistic & $p$-value \\
\hline Bi-Level Airlift Loading System (BALS) & $17,077.48$ & $9,502.60$ & 1.80 & 0.084 & Table II. \\
Tonneau covers & $88,671.98$ & $60,268.21$ & 1.47 & 0.154 & Cost savings \\
Aggregation & $123,063.26$ & $27,657.00$ & 4.45 & 0.001 & regressed on \\
Dual rail swap & $21,512.41$ & $7,188.24$ & 2.99 & 0.006 & techniques \\
C-17A cargo compartment configuration & $8,761.84$ & $9,971.33$ & 0.88 & 0.388 & \\
\hline
\end{tabular}


JDAL 1,2

movement size. A single C-130J-30 accounted for 8 PPs, a single C-17A accounted for 18 PPs and a C-5B/M accounted for 36 PPs.

\section{Discussion}

Our findings can be extrapolated to reveal the potential impact of these techniques. Of the movements provided by the load planners, only 22 per cent of the load plans were within the scope of this study. This provided us with a scalability factor that we used to extrapolate the multi-year implications of our findings. A total mission report was pulled from the Global Decision Support System for 2013, 2014, 2015 and 2016. The report was tailored down to both military and civilian cargo airlift sorties that included total contingencies, channel, Special Airlift Assignment Missions, support, ground-lift, deployment, exercises and tanker-lift. Once the airlift missions for the year were totaled, the outcome was multiplied by 22 per cent for the scalability from the data collected in this research. After adjusting for scalability, the resulting sorties were multiplied by $\$ 91,251$, which represents the average observed savings per sortie based on this research. Table III depicts the potential savings from 2013, 2014 and 2015.

\section{Conclusion}

Low utilization rates for cargo airlift have been a problem for many years. This dilemma drives up cost and constrains limited resources that could be directed toward other efforts. The techniques analyzed in the research have shown that they will increase utilization rates, allowing airlift to get closer to the maximum routing ACL. The total number of airlift aircraft for the given set of cargo requirements was reduced by almost 25 per cent. Two of the most influential techniques (aggregation and dual rail swap) required no additional 463L equipment and could be implemented immediately through policy changes and load planning re-education efforts.

Despite the efficiency gains identified in this study, the average utilization found across all 159 sorties was 55.52 per cent of cargo throughput optimized routing ACL. That is, 44.48 per cent of cargo airlift capacity would continue to go unused. If all of the techniques analyzed in this study are incorporated into day-to-day operations, the airlift community would still only be able to use a little over half of available capacity.

The techniques analyzed in this study are not new. It would be helpful if future research could help explain why these techniques are not being used effectively now. One possibility is that in retrospect it is easy to aggregate cargo and load plan, but in real time, effectiveness is desired over potential efficiencies. Another possibility is that there is a lack of policy and lack of adequate training on the specific techniques mentioned in our analysis. As technology advances, additional cargo loading efficiency techniques should be explored, developed and tested. These studies could further enhance cargo load planning and execution to improve efficiency and save taxpayer money.

\begin{tabular}{cccc}
\hline Year & Sorties & Scaled sorties & Potential savings \\
\hline 2013 & 87,843 & 19,325 & $\$ 1.76 \mathrm{~B}$ \\
2014 & 79,372 & 17,462 & $\$ 1.59 \mathrm{~B}$ \\
2015 & 73,061 & 16,073 & $\$ 1.47 \mathrm{~B}$ \\
\hline
\end{tabular}

Table III. 


\section{References}

Abalateo, M.D. and Lee, J.R. (1993), "benchmarking practices of air cargo carriers: a case study approach", Masters, Air Force Institute of Technology, Wright-Patterson AFB.

Air Mobility Command (2014), AMC Affiliated Contingency Load Planning Workbook 36-101 Volume 2: Airlift Planners Course, Air Mobility Command, Illinois.

Chao, C.C. and Li, R.G. (2015), "Effects of cargo types and load efficiency on airline cargo revenues", Journal of Air Transport Management, Vol. 61, pp. 26-33.

Chocolaad, C.A. (1998), "Solving geometric knapsack problems using tabu search heuristics”, Masters, Air Force Institute of Technology, Wright-Patterson AFB.

Cochard, D.D. and Yost, K.A. (1985), "Improving utilization of air force cargo aircraft", Interfaces, Vol. 15 No. 1, pp. 53-68.

Department of the Air Force (2010), Technical Order 1C-17A-9: Loading Instructions United States Air Force Series C-17A Aircraft, Department of the Air Force, Pentagon.

Department of the Air Force (2012), Air Force Manual 24-204: Preparing Hazardous Materials for Military Air Shipment, Department of the Air Force, Pentagon.

Fok, K., and and Chun, A. (2004), "Optimizing air cargo load planning and analysis", Proceedings of the International Conference on Computing, Communications and Control Technologies, Austin, TX, 14-17 August.

Gray, M.S. (2010), “The effects of cargo height distribution on B-747 and C-17 Airlift”, Masters, Air Force Institute of Technology, Wright-Patterson AFB.

Gyokeres, P. (2012), "US Air Force airmen assigned to the 621st contingency response wing at joint base McGuire-Dix-Lakehurst, N.J. fly aboard a JB MDL-based C-17 Globemaster III", available at: www.af.mil/News/Photos/igphoto/2000102192/mediaid/11030/ (accessed 27 February 2018).

Harrison, T. (2014), Analysis of the FY 2015 Defense Budget, Center for Strategic and Budgetary Assessments, Washington, DC.

Lau, H.C.W., Chan, T.M., Tsui, W.T., Ho, G.T.S. and Choy, K.L. (2009), "An AI approach for optimizing multi-pallet loading operations”, Expert Systems with Applications, Vol. 36 No. 3, pp. 4296-4312.

Limbourg, S., Schyns, M. and Laporte, G. (2012), “Automatic aircraft cargo load planning”, Journal of the Operational Research Society, Vol. 63 No. 9, pp. 1271-1283.

Maywald, J.D. (2016), "Reducing airlift inefficiency through aircraft selection modeling", Masters, Air Force Institute of Technology, Wright-Patterson AFB.

Mongeau, M. and Bes, C. (2003), "Optimization of aircraft container loading”, IEEE Transactions on Aerospace and Electronic Systems, Vol. 39 No. 1, pp. 140-150.

Nance, L. (2009), "An advance tabu search approach to solving the mixed payload airlift load planning problem”, Masters, Air Force Institute of Technology, Wright-Patterson AFB.

Ng, K.Y.K. (1992), "A multicriteria optimization approach to aircraft loading”, Operations Research, Vol. 40 No. 6, pp. 1200-1205.

Reiman, A.D. (2014), "Enterprise analysis of strategic airlift to obtain competitive advantage through fuel efficiency", PhD, Air Force Institute of Technology, Wright-Patterson AFB.

Reiman, A.D., Main, B.D. and Anderson, B.E. (2015), "Enhancing airlift fuel efficiency through increased utilization of cargo capacity", The Journal of Defense Modeling and Simulation: Applications, Methodology, Technology, Vol. 12 No. 1, pp. $19-29$.

USAF Scientific Advisory Board (1997), United States Air Force Expeditionary Forces, USAF Scientific Advisory Board, Washington.

Vatcher, A. and Maynard, K. (2004), "Bi-level aircraft loading system (BALS)". 
JDAL

1,2

150

Vincelli, A. (2004), "Idaho air guard helps test new stackable cargo pallets", available at: www.af.mil/News/ Article-Display/Article/137056/idaho-air-guard-helps-test-new-stackable-cargo-pallets/ (accessed 27 February 2018).

Wilson, C.L. (2016), "Increased capacity utilizing aggregation and consolidation of Contingency Cargo", Masters, Air Force Institute of Technology, Wright-Patterson AFB.

Wilson, S.J. (2011), "The impact of increased pallet utilization on intra-theater airlift", Masters, Air Force Institute of Technology, Wright-Patterson AFB.

\section{Further reading}

Department of Defense (2016), Defense Transpoprtation Regulation: Part III Mobility, Department of Defense, NJ.

\section{Corresponding author}

Robert E. Overstreet can be contacted at: robert.e.overstreet@gmail.com

For instructions on how to order reprints of this article, please visit our website: 